\title{
Climate Change Communication and Public Engagement in Interpersonal Deliberative Settings: Evidence from the Irish Citizens' Assembly.
}

\author{
Lala Muradova*, Hayley Walker ${ }^{+*}$, Francesca Colli ${ }^{*}$ \\ ${ }^{*}$ University of Leuven (Belgium) \\ ${ }^{+}$Université Catolique de Louvain (Belgium)
}

\section{Introduction}

A perceived lack of public support or legitimacy is a major barrier to ambitious national climate policy (Drews and van den Bergh 2016; Lockwood 2011). Many of the most effective greenhouse gas (GHG) mitigation measures, such as a meaningful carbon tax, investment in renewable energy and incentives for land use change, pose short- to mid-term costs for constituents. Governments are often reluctant to adopt the necessary policies to meet the goals set out in the Paris Agreement because they fear reprisals in the ballot box. Deliberative mini-publics, whereby a sample of lay-people, (usually) demographically representative of the larger population, convened to discuss and reflect on a political issue before making policy recommendations, have been proposed as a means of bringing credibility and legitimacy to political decision-making and tackling the disconnect between citizens and the unique challenges posed by climate change (Stevenson and Dryzek 2014). "Talk-centric" deliberative approaches serve not only to enhance democratic legitimacy of collective decisions, but can also lead to support for more ambitious climate policy through the prioritisation of the commons over selfinterest, providing alternative perspectives and potential solutions, and facilitating greater coherence and consensus across highly complex issue areas (Niemeyer 2013). However, the majority of such deliberative fora have limited or no influence on actual policy making (Smith and Setälä 2018). 
Ireland is a notable exception that appears to be "systematizing" (Farrell, Suiter, and Harris 2019) public deliberation into its policy cycle. From 2012-2014 a mini-public - the Irish Constitutional Convention (ICC) - was convened to deliberate on marriage equality (together with eight other issues), leading to a national referendum on the topic in 2015. The advent of the Irish Citizens' Assembly broadened the scope of the democratic experiment. The Assembly brought together 99 participants, ${ }^{1}$ selected randomly to broadly represent the electorate, to discuss a number of key policy areas including abortion and climate change, with the express purpose of forwarding legislative proposals to the Oireachtas (Irish parliament) for consideration. Citizens first received a number of expert and nonexpert inputs on climate change including over 1,200 written submissions, oral presentations and question and answer (Q\&A) sessions with 21 speakers, and subsequently engaged in deliberation in small groups. On climate change, the Assembly participants decided on 13 policy recommendations that were "significantly more radical than many expected" (Torney and O'Gorman 2019, 11). These included raising the carbon tax, support for land use change, including reforestation, and a tax on agricultural GHG emissions: precisely the kind of measures that would be deemed too politically costly for an agriculture-dependent society like Ireland. The Assembly's recommendations were sent to the Oireachtas and in June 2019 the government announced an ambitious suite of climate measures. Although it stopped short of adopting the Assembly's most controversial recommendations for the agricultural sector, the plans include the "politically fraught exercise" (Carroll 2019) of hiking the

\footnotetext{
${ }^{1}$ In practice, there was a large turnover in membership and several rounds of recruitment were implemented with an objective of filling the gaps of those who dropped out. There were in total 152 citizens recruited over the life of the Irish Citizens' Assembly (15 months). 83 and 80 ICA members attended respectively the first and second weekend of climate change deliberations (see Farrell et al., 2019).
} 
carbon tax from $€ 20$ to $€ 80$ per tonne and increasing the share of renewables in the energy mix from $30 \%$ to $70 \%$, both before 2030 . For a climate laggard that has consistently failed to meet its EU targets (Torney and O'Gorman 2019), this represents an extraordinary move.

Despite the far-reaching implications of the Irish climate case, it has received scant academic attention. Given that the mini-public was able to decide on policy proposals that far surpassed the political level of ambition in Ireland and that the proposals look set to become national policy, it is surprising that no one has questioned why these specific recommendations were forwarded to the government and how expert information played a role in these processes. This article contributes to filling this gap. Engagement with and support for climate policy is a complex matter involving multiple factors operating at different levels of analysis. Individual-level factors include one's worldview, values and political orientation (Drews and van den Bergh 2016). Each member of the Assembly brought a unique combination of political views and life experiences; yet, the wording of the draft ballot paper with policy recommendations was reached by consensus. Country-level factors pertain to economic and political considerations, such as an economic dependence on climate-detrimental fuel production (Harring, Jagers, and Matti 2019). These fail to explain the surprising recommendations of the Irish Citizens' Assembly, for example, the agricultural GHG tax in the context of an agriculture-dependent society, or the recommendation to ban peat extraction subsidies, a highly damaging fuel source that has long been a key part of Ireland's energy mix. This paper therefore takes a different approach. It focuses on the effectiveness of climate change communication in deliberative settings as a condition that can explain citizens' policy-uptake, and in so doing contributes to the rich literature on climate change communication. 
Effective communication is operationalised using the principles outlined in the handbook that was recently produced for authors of the Intergovernmental Panel on Climate Change (IPCC) (Corner, Shaw, and Clarke 2018). We code video recordings of the 21 presentations according to these principles. Additionally, we code the number and nature of proposals made by each speaker during the presentations and Q\&A sessions. To measure members' uptake of the speakers' proposals, we analyse the policy recommendation document that was forwarded to the Oireachtas for further action, using systematic text analysis. We test our expectations using fuzzy-set qualitative comparative analysis (fsQCA) (Ragin 1989, 2008). The results indicate that effective communication is a necessary component of policy uptake, but is not sufficient on its own for the Assembly to include most of a speaker's proposals in its recommendations. Other factors, such as the repetition of the policy proposal by other speakers and uniqueness of the message communicated by non-expert speakers, also play a role.

These findings have important practical implications for policymakers. Unlike individual- or countrylevel factors that are not easily subject to change by those wishing to promote more ambitious climate action at the national level, the way in which information is communicated represents low-hanging fruit. Since other governments, including the UK and France, are now following Ireland's example and using deliberative fora as a means to build public support and legitimacy for ambitious climate policy, it is imperative to draw lessons from this landmark case.

The following section surveys the literature on deliberative democracy and shows how we expand this scholarship with a novel contribution on the role of effectiveness of expert communication on climate change on citizen deliberators' policy uptake in interpersonal deliberative settings. We then turn to the scholarship on climate change communication for insights to inform our theorisation and 
operationalisation of effective communication. This is followed by presenting our case study and methodology. We proceed to present the results of the QCA analysis and conclude by discussing the implications of these findings.

\section{Deliberative democracy and expert communication}

Deliberative democratic theorists and practitioners argue that representative democracy should be complemented by a more talk-centric deliberative democracy whereby citizens (and politicians) engage in inclusive public decision-making processes, discuss and consider the issues that directly affect them and arrive at more legitimate, informed and reflective political decisions. Deliberative ideas have spawned a wide variety of citizen participation efforts around the world, ranging from small town hall meetings at one end of the spectrum, through citizen juries, citizens' initiative reviews and mini-publics. An institutionalised national event like the ICC falls at the other end of the spectrum.

These deliberative public fora usually engage a randomly chosen cross-section of lay citizens convened to study a particular issue in open discussions overseen by professional facilitators. They involve an "information phase" whereby participants absorb and reflect on the content of written packs, expert presentations and testimonies of non-expert advocates, followed by a "deliberative phase" whereby participants come together to consider different issues and problems from diverse angles; share arguments, personal stories, and narratives; and come to more considered political judgements, under the conditions of respect and equality. 
Deliberative approaches to climate policy rest on the assumption that direct citizen engagement in policy making via public discussion leads to more informed, reflective and ambitious policies. Proponents argue that in creating an environment where citizens can learn from experts and express their arguments and perspectives freely, they better understand each other's concerns and thus come to more multi-faceted and reflective decisions, as opposed to narrow-minded and self-interested ones (see Bächtiger et al. 2018 for a review). Scholars argue that public deliberation on these issues is particularly better positioned to emphasise the less tangible dimensions of climate change, which might be pushed aside or intentionally distorted by public debate, and thus provide the public with a more thorough and sound vision of the environmental challenges posed (Niemeyer 2013). Others emphasise the power of deliberation in bringing together the interests of those who cannot represent themselves in the discussions, such as "future generations, distant others, and non-human nature" (Dryzek 2010).

The common assumption is that such benefits arise from the deliberative stage of the process. Indeed, this two-way "communication [that] induces reflection on preferences in non-coercive fashion" (Dryzek 2010,10) constitutes the heart of many theories of deliberative democracy. Another stage of deliberation - expert information - is an equally important element of real-world mini-publics. Citizen deliberation on issues of societal importance necessitate adequate information and empirical evidence (Baekkeskov and Öberg, 2016). Expert information is particularly critical for shedding light on complex and technical issues, such as climate change. ${ }^{2}$ Further, prior research suggests that outcomes

\footnotetext{
${ }^{2}$ Of course, expert information, in isolation, has a limited effect on public deliberation. It cannot per se resolve basic moral issues (Gutmann and Thompson, 2004; Brown, 2014); or unearth different perspectives and points of view that citizens from different walks of life may bring to the table.
} 
might be induced by the information phase, rather than the deliberative phase. For example, Goodin and Niemeyer (2003) surveyed participants of an Australian citizens' jury convened to discuss an environmental issue. They measured preferences for various policy options at the beginning of the process, after the information phase and then finally after the deliberative phase. Their results showed that the significant change occurred after the information phase (Fournier et al. 2011; but O’Malley et al., 2019).

Surprisingly, with a few notable exceptions (e.g. Roberts et al., 2020; O’Malley et al., 2019), there has been little empirical research on how information communicated by speakers in mini-publics is consequential for deliberative outcomes with real-world implications. What are the desirable communicative qualities of expert (and non-expert) speakers on climate change? Does the way in which a speaker communicates influence engagement with and support for the policies they propose? In this paper we contribute to answering these questions by studying the role of expert (and nonexpert) communication in citizen deliberators' uptake of policy proposals on climate change.

\section{Effective communication on climate policy}

The "information deficit" model argues that citizens' lack of support for climate policy results from a lack of scientific knowledge and an inability to understand the complexities of the issue, and proposes providing more information as a solution (see Suldovsky, 2016 for a review). However, a substantial body of research on cognitive biases and heuristics has convincingly demonstrated that humans do not

Expertise needs to be subject to public scrutiny (Brown, 2014; Roberts et al., 2020). Studying the relative importance of expert information over deliberation is beyond the scope of this paper. 
process and act upon information rationally, but rather employ a range of heuristics to short-circuit the slow and cumbersome apparatus of rationality when handling the overwhelming quantity of information that the mind processes on a daily basis (see Suldovsky, 2016 for other critiques). These cognitive short-cuts are contingent on subjectivity, emotion and affect, and so depend as much on the individual listener as on the content of the message. Simply increasing the supply of information will not therefore have the desired effect.

Instead, individuals' opinions on climate change are a means of expressing their identity and social values, rather than a consequence of scientific literacy (Kahan et al. 2012). Climate change communicators should therefore be aware of the audience they are speaking to and appeal to the values held by their audience. Avoiding waste, the concept of "balance" between humans and the environment and the local impacts of climate change are all values that have been found to resonate across the political spectrum (O’Neill and Nicholson-Cole 2009). This is where, we argue, the effectiveness of the communicator plays a major role. An effective communicator, in this paper, is conceptualised as a speaker who conveys information on climate change (1) that resonates well with daily lives and values of lay people, (2) in accessible language in a narrative format; and (3) in a convincing and authentic manner. For this conceptualisation we build upon the extant literature on climate change communication.

Climate change communication scholarship increasingly recognises the importance of stories, narratives and metaphors (Moezzi, Janda, and Rotmann 2017). Traditional ways of communicating climate change and other global environmental problems that are abstract in nature and not directly experienced are not aligned with the cognitive processes through which people acquire and process 
information. Stories, on the other hand, take advantage of these processes because they are "inherently interesting, provide concrete examples of abstract issues or concepts (...), can be crafted to relate to people's lives and what they already know" (Kearney 1994, 434). Cognitive activation is more likely to occur when the information received is interesting for the listener, relates to her prior knowledge, contains vivid details and is concrete rather than abstract, making stories the "natural form of public engagement" (Shaw and Corner 2017).

The benefits of using stories, narratives and metaphors in communicating climate change go beyond cognitive processing. Everyday language and metaphors allow for the recognition of climate change as a personally relevant issue (Shaw and Corner 2017) and stories can contain emotionally and culturally relevant information that is lacking from traditional ways of communicating climate change (Moezzi et al. 2017). Lastly, for their message to be heard, the speakers need to build trust with their audiences. Scientific and abstract language risks leading to feelings of exclusion, mistrust and/or defensiveness (Shaw and Corner 2017). The extent to which speakers communicate confidently and authentically is a further driver of building trust with the audience (Corner, Shaw and Clarke, 2018).

The goal of this study is to test whether effective communication can contribute to explaining the outcome of deliberation on climate change in the highly impactful setting of the Irish Citizens' Assembly. Building on the aforementioned literature, our main theoretical expectation is that citizens' support for policy proposals can be explained by communicator effectiveness. 


\section{Measuring Effective Communication}

To operationalise and capture effective communication, we rely on Corner, et al. (2018). Whereas other measurements of effective climate change communication focus on the receivers of the message (e.g. Kahan 2015), the IPCC handbook (Climate Outreach 2018, hereinafter referred to as 'the handbook')

(Corner, et al., 2018) is built on evidence-based principles of effective climate change communication for senders of the message. The IPCC is the leading organisation responsible for assessing climate change science and communicating findings to policymakers and the broader public. The handbook sets out six principles for effective communication on climate change, which constitute our proxies for effective communication for two main reasons. First, the content is highly relevant for investigating expert communication in deliberative fora and reflects our theoretical expectations. Climate Outreach is an authority on climate change communication research and the extent and depth of the review upon which the handbook rests are greater than anything that could have been developed for this paper. Second, given that the handbook is specifically targeted at climate experts who might be invited to speak at deliberative events, examining whether the advice prescribed matches what works in practice seems pertinent. This study therefore represents a real-life test for the guidelines prescribed in the handbook.

The six principles are as follows: (a) be a confident communication; (b) talk about the real world, not abstract ideas; (c) connect with what matters to your audience; (d) tell a human story; (e) lead with what you know; and (f) use the most effective visual communication. The principles (b), (c) and (d) capture the first and second components of our concept ((information that resonates well with daily lives and values of lay people communicated in accessible language in a narrative format) whereas the 
principles (a), (e) and (f) are proxies for the third component (speaking in a convincing and authentic manner).

\section{Other Conditions}

In addition to effectiveness of climate change communication, we expect a number of other speakerlevel conditions to interact with effective communication in affecting the uptake of policy proposals. First, we expect discursive differences in communicating climate change among different types of speakers and for these differences to be reflected in members' engagement with the speaker's messages.

In organised deliberative settings, there are usually two types of speakers: experts and non-experts ("witnesses"). Experts are academics or policy makers specialised in different aspects of the issue under discussion. Witnesses are non-experts, called upon to give (usually personal) evidence and/or advocate for a cause. At the ICA on climate change, experts presented mostly scientific information, while witnesses shared their personal experiences in combating environmental challenges. For example, one witness was a champion in mobilising his colleagues to recycle and save energy in the workplace. Another witness had founded a non-profit company to address the problem of food waste while simultaneously providing impoverished citizens with free food.

Second, recent research has emphasised gender asymmetries in discursive influence of communicators. Beauvais (2019) finds that both men and women are more open to revise their opinions after having received an identical counterargument coming from a male communicator than from a female communicator. Accounting for potential gender differences in communication is therefore paramount. 
In addition to communicator differences, we account for two factors related to policy proposals. Previous research suggests that moderate levels of repetition of the same message can result in the message being better understood and perceived as more credible (Ernst, Kühne, and Wirth 2017; Cacioppo and Petty 1989). Two mechanisms have been proposed. First, repetition can increase the perceived credibility of the message via unconscious and memory-based processes. Second, exposure to the same message repeatedly can improve and facilitate information processing. A third possibility, in our case, is that certain proposals are particularly prominent in Irish climate policy circles and thus are more likely to be picked up by a number of speakers. Building on this body of work, we expect that repetition of the same policy proposal may positively affect citizens' engagement with that policy proposal.

\section{The Irish Citizens' Assembly (ICA)}

The ICA was a deliberative body established in 2016 consisting of 99 citizens (and a chair). The Assembly met on 12 occasions to deliberate on five important issues facing Irish society: the 8th amendment to the constitution; the aging population; climate change; referenda and fixed-term parliaments (see Farrell, Suiter, \& Harris, 2019). After deliberations on each topic, Assembly members'

conclusions were compiled into reports and recommendations and submitted to the Houses of Oireachtas to be debated and acted upon. One of the topics considered by the Assembly was climate change, more specifically titled "How the State can make Ireland a leader in tackling climate change", which was discussed during the weekends of 30 September-1 October and 4-5 November 2017. 
Prior to deliberations the Assembly received 1200 submissions from the larger population, civil society organisations, lobbyists etc. (Devaney et al., 2020). A 'signpost document' containing an overview of these submissions was prepared by the chair of the Assembly and distributed among the members for consideration. Deliberations mostly focused on the pre-determined policy areas of energy, transport and agriculture. The information phase of the deliberations, consisting of presentations by 21 speakers and four Q\&A sessions, was live-streamed on the Assembly website. In addition, one of the authors of this manuscript observed all the meetings on climate change and interviewed eleven members of the Assembly (author, forthcoming).

The Steering Group, consisting of the chair and a representative group of members elected by the members of the Irish Citizens' Assembly, shaped the choice of the speakers. During this process, the Expert Advisory Body, was also consulted (see www.citizensassembly.ie for more info). The main criteria behind choosing experts was to ensure a wide range of balanced perspectives in terms of content and substance provided by the speakers and the experts to be good communicators, broadly defined (informal interview with an expert from the Expert Advisory Body).

After two weeks of deliberations, the Assembly's recommendations were voted on by each citizen deliberator and decided by majority vote. There were 13 policy recommendations forwarded to the Oireachtas. Among others, the Assembly recommended that the government (a) put climate change at the centre of policy making in Ireland, by creating a new independent body responsible for this purpose; (b) impose higher taxes on carbon-intensive activities; and (c) introduce mitigation measures including retrofitting public buildings and low-carbon public vehicles. The 13 recommendations and the subsequent Parliamentary Committee recommendations significantly shaped the Irish government's landmark Climate Action Plan, published in June 2019 (Coleman et al., 2019). The goals in the Action Plan echo the recommendations of the Assembly: reducing greenhouse gas emissions to 
net zero by 2050, rolling down its coal- and peat-fired power generation, making car and van sales 100\% electric by 2030 and imposing stricter energy-efficiency standards for buildings (Darby, 2019). The Irish government has taken concrete action towards implementing the enhanced carbon tax: the parliamentary committee voted to back this proposal, as a result of which the carbon tax on fuel has already increased by $€ 6$ per tonne. This action constitutes a first step in a larger government policy to increase the carbon tax from $€ 20$ to $€ 80$ per tonne by 2030 (RTE, 2019).

\section{Method}

The objective of this study is to examine the question of whether effectiveness of climate change communication affects citizens' uptake of policy proposals in deliberative settings. In order to answer this question, we proceeded as follows. First, we developed a coding scheme that operationalises the six principles outlined in IPCC guidelines. Second, we trained the coders on this coding scheme. . We applied holistic coding (Hawkins 2009) to code speakers' communication effectiveness, whereby the coders watched the presentation in its entirety, twice, and gave scores based upon their overall impression of communicative elements, outlined in the coding scheme. $20 \%$ of the data was coded by a secondary coder. The results of the inter-coder reliability tests were unsatisfactory for three questions. These questions contained the finest degrees of discrimination, which led to higher subjectivity (i.e. there was a clear difference between 0 and 1, but much smaller difference between 2 and 3). We therefore removed one degree of discrimination (i.e. we merged 2 and 3) and the secondary coder repeated the tests (McHugh 2012). It is important to note that there are still clear differences between 
the scores, meaning that merging the last two scores does not affect our operationalization. The results of the second round of test were high (on average $82 \%$ agreement across six items) ${ }^{3}$.

Next, speakers' policy proposals were coded separately by two authors with expertise in climate policy. The same holistic approach was employed. Again, each presentation was watched twice in its entirety (alongside the Q\&A sessions) to ensure that nothing was missed. For an idea expressed by a speaker to be considered a policy proposal, it could not refer to climate policies already in place in Ireland. Each of the speaker's proposals was given a score (0-3) based on whether it appeared on the ballot paper almost exactly as proposed (3), with the main idea but in an alternative formulation (2) or as a related topic but not the speaker's direct proposal (1). If a recommendation did not end up on the final ballot at all it was scored 0 . The scores of both coders were either a match or within one point for all speakers. For those speakers where there was not an exact match, the coders discussed until they reached agreement.

To analyse the data, we take a set-theoretic approach, using fuzzy-set qualitative comparative analysis (fsQCA) to operationalise conditions and analyse the data (Goertz 2006; Ragin 1989, 2008). QCA relies on set theory (the membership of variables or 'conditions' to sets) to uncover combinations of conditions that lead to a particular outcome, also known as 'paths' or 'configurations'. This method

\footnotetext{
${ }^{3}$ More specifically, the percentage agreement for each item was the following: $100 \%, 75 \%, 75 \%, 50 \%$, $92 \%$, and $100 \%$. More detailed information on the operationalisation of the handbook principles and the development of the coding system, as well as on alternative intercoder reliability measure (e.g. Cohen's Kappa) can be found in Appendix A.
} 
was chosen for three main reasons. First, the objective of the research is to explain why the outcome occurred - why some speakers were successful in getting their proposals put on the ballot and others were not and effective communication played a role in these processes. We take the stance that there is significant causal complexity in this relationship, and thus do not aim to purely examine the effect of individual independent variables. Second, QCA allows us to both test existing theories - by including variables that are identified as important in the climate change communication and deliberation literatures - but still maintain a somewhat exploratory stance, as QCA results automatically includes all configurations of the variables included in the analysis. Finally, in practical terms, the limited number of speakers (21) lends itself well to set-theoretic research, as it is too large to use comparative case studies but too small for regression analysis.

The measurements for the conditions were subsequently calibrated into fuzzy sets. A word of explanation is warranted for the condition 'effective communication (EFF)', the only aggregate condition in the QCA. As explained above, this measure was based on the six indicators of effective climate communication, which were scored by coders from the speakers' presentations. Each of the six indicators was calibrated individually, before being aggregated through set-theoretic logic (Goertz 2006). We split the notion of 'effective communication' into two parts: the delivery (presentation style) and the content of the message (whether the speaker remains concrete, tells stories and refers to local values - important aspects of climate change communication, as we have discussed above). Both of these are necessary for a speaker to be considered an effective communicator; however, the way in which a speaker makes their message relate to the local level can vary. 
The outcome - a high proportion of a speaker's proposals ending up on the final ballot (PROP) - is a proxy measurement for the success with which a particular speaker communicated to the audience, as the final ballot of recommendations was decided by majority vote by the citizen deliberators. The average score per recommendation per speaker was then calculated by adding up all of a speaker's scores and dividing the total score by the number of proposals; this was calibrated into a fuzzy set using the direct method of calibration (Ragin 2008). ${ }^{4}$ The conditions are summarised in the table below, and more detail on this aggregation logic can be found in Appendix B.

Further, we categorised speakers as either expert or witness consistent with the Assembly report, which identified 15 speakers as "experts" and 6 speakers as "individuals who shared their personal experience of becoming a leader in the area of climate change in Ireland" (Citizens' Assembly, 2018, p. 2). We also included other conditions (gender, repetition, number of proposals).

Finally, in initial analyses, we also accounted for the costliness of policy proposals. An expert interviewee from the Assembly Expert Advisory Body highlighted that three policy proposals were considered to be particularly sensitive during the Assembly due to their indirect or direct costs on citizens: a carbon tax, agricultural tax, and removal of subsidies for peat extraction. However, including this condition in our model gave no meaningful results. We believe that this may be due to the level of aggregation of the analysis: given that most speakers mixed both costly and non-costly proposals,

\footnotetext{
${ }^{4}$ The direct method of calibration plots all scores onto a logistic function, around thresholds set by the researcher.
} 
the effect was not visible at speaker level. We therefore do not report it in this paper. However, this factor would be interesting to include in an analysis at the proposal level.

Table 1 bere

\section{Results}

This section outlines the results of the QCA. We present the enhanced intermediate solution here (Schneider and Wagemann 2012, 209) as it is simple enough to be interpretable, while relying on theoretical expectations for single conditions and ensuring that no combination of conditions is assumed to lead to both the outcome and its opposite. All analyses were carried out using statistical software R and its packages of QCA and SetMethods (Dusa, 2019; Oana and Schneider, 2018). Details of all other solutions, truth tables and XY plots are presented in Appendix B.

We present three models. The first includes three conditions: effective communication, a high proportion of repeated proposals and a high number of total proposals made by the speaker. The second includes these three conditions, plus the gender of the speaker. The final model replaces the gender condition with a speaker-type condition (i.e. whether the speaker was an expert chosen for subject-specific expertise or a non-expert chosen for their personal experience and testimony). The outcome for all three models was a speaker achieving a high proportion of their proposals on the ballot paper (PROP). We first present the three models, before discussing the results below.

\section{Table 2 bere}




\section{Model 1 here}

The full solution term for the first model is EFF*NO + REP NO $\rightarrow$ PROP. In other words, an effective speaker who presents a high number of proposals, or a speaker who presents a lower number of proposals but whose proposals are repeated by others, got a high proportion of their proposals on the ballot.

\section{Model 2 here}

The complete solution expression for this model was reasonably similar: EFF*NO + REP*MALE + $\mathrm{EFF}^{*} \sim \mathrm{REP} * \sim \mathrm{MALE} \rightarrow$ PROP. Again, effective speakers who make a high number of proposals get a high proportion of proposals on the ballot. Male speakers - effective communicators or not - whose proposals are repeated by others also get a high proportion of proposals on the ballot; in contrast, effective female speakers who are not repeated are successful.

Model 3 here

The solution term here, while more complex than in previous models, indicates that - rather surprisingly - the effect of a high number of proposals is different for experts and witnesses. Effective speakers whose proposals are repeated get a high proportion of their proposals on the ballot, whether or not they are experts. Effective expert speakers who present a high number of proposals have a high proportion put on the ballot - clarifying the findings from the previous two models (EFF*NO). On the other hand, non-experts who do not present a large number of proposals and who are either effective speakers or are repeated by other speakers get a high proportion of their proposals put on the ballot. This effect provides suggestive evidence that audiences listen to experts and non-experts under different conditions. These somewhat puzzling results are discussed in the section below. 


\section{Discussion}

The results of the three models above indicate that being an effective communicator is always important. However, by itself, it is not sufficient. In addition, there are two main paths leading to uptake of a speaker's proposals. The first path, repetition, highlights that if a high proportion of a speaker's proposals are repeated by other speakers, then the audience takes up a high proportion of those proposals for the ballot. This is evident in different paths across the models: REP* NO*( EXP), EFF*REP and REP*MALE.

We see three main possible explanations for this ‘repetition' path. The first two are founded in existing work on the topic: repetition may facilitate recall or provide support and evidence for a particular proposal - if enough different speakers repeat an idea, it must be a good one (Ernst, Kühne and Wirth 2017; Cacioppo and Petty 1989). An alternative explanation is that the ideas that are repeated are prominent in Irish climate change debates - this prominence would thereby explain both their repetition by multiple speakers and their uptake by Assembly participants. It is true that the proposals that were most repeated were more general ones (such as wind energy and electric vehicles) compared to more sector-specific or technical proposals. This may imply that it may not be repetition itself, but rather the nature of the proposals that are repeated, that leads to uptake; or in other words, limit the applicability of the effect of repetition to more broad proposals. An example of this kind of case is speaker T. Speaker T made nine policy proposals, of which five ended up on the final ballot. Apart from one proposal, all of speaker T's accepted proposals were repeated up to seven times by others, and sometimes made more explicitly elsewhere. 
The second path is uniqueness: if a speaker can make themselves stand out from the crowd, a high proportion of their proposals end up on the ballot. The way that speakers cultivate this uniqueness, however, seems to be different for experts and witnesses. For experts, being an effective communicator and presenting a high number of proposals $\left(\mathrm{EFF}^{*} \mathrm{NO}\left({ }^{*} \mathrm{EXP}\right)\right)$ leads to a high number of proposals being adopted. Speaker R, for example, was an expert discussing best practices implemented by a local council. This speaker was an effective communicator who made seven proposals on a range of policy areas. Five of these proposals appeared on the final ballot, of which four were either exact or direct matches of speaker R's ideas. In contrast, for witnesses, the opposite is true: being an effective speaker but presenting only few proposals ( $\left.\mathrm{EFF}^{*} \sim \mathrm{NO}^{*} \sim \mathrm{EXP}\right)$ leads to a high proportion of those proposals being put on the ballot. ${ }^{5}$ For example, Speaker I, a witness, was an effective communicator who presented only four recommendations on a single topic: food waste. Two of these recommendations were taken up by the Assembly, despite the fact that Speaker I was the only speaker to mention food waste. These two typical cases demonstrate the difference between experts and witnesses who are effective communicators: experts can have an impact by presenting a high number of proposals, whereas witnesses should focus on a simple, unique message.

How can we explain this puzzling finding that for non-experts, having a lower total number of proposals helps them to get a higher proportion of their recommendations on the ballot? Prior theorisation does not exist, to the best of our knowledge, that would adequately explain this result,

\footnotetext{
${ }^{5}$ The expression EFF* ${ }^{*} \mathrm{REP}^{*} \sim \mathrm{MALE}$ may also fit this path: there were significantly fewer women speakers than men (only 6 of the 21 speakers were female), so effective female speakers may have been more easily able to stand out to the audience.
} 
which arose as a consequence of the exploratory nature of the QCA method, and so we limit ourselves to some speculative hypotheses. It may be that audiences expect expert speakers to be informed across a broad spectrum of policy areas, thus allowing those experts who present a large number and variety of proposals to distinguish themselves. In contrast, putting forward a wide range of facts and recommendations may not be beneficial in the context of presenting one's personal testimony, and so those non-experts who effectively advocate for a single cause - in a narrative format that resonates with people's everyday realities - see greater engagement with their message.

\section{Conclusion}

The climate emergency requires strong public support in order to implement ambitious climate policies. One way to boost public support for ambitious climate policy is to involve ordinary citizens in climate policy-making. Ireland has become a trailblazer in its recent citizen-centred approach to tackling climate change. A citizen assembly of randomly selected Irish citizens from all walks of life discussed climate change and agreed upon climate policies that far surpassed the government's existing level of ambition: higher and wider carbon tax; increased incentives for electric vehicles; more public transport and end to the subsidies for peat extraction. Its success has inspired calls for more citizens' assemblies and several ambitious citizen-centred experiments across the world. The objective of this paper was to study the role of information communicated to citizens on their uptake of climate change policy proposals in the framework of this unique real-world deliberative event.

Our results support our expectation that effective communication, conceptualised as communication conveyed in accessible language in a narrative format, reflecting daily lives and values of lay citizens and delivered in an authentic and convincing way, does affect deliberative outcomes: effective 
communicators across all conditions saw a greater proportion of their policy proposals taken up by the Assembly in the recommendations they forwarded to the government

Our findings have implications for several strands of literature. First, they lend weight to the importance of the information phase in deliberation, often overlooked in scholarship on deliberative democracy (see also Roberts et al., 2020). Policy uptake by citizens may (at least partially) depend on the way in which experts present this evidence. In doing so, we do not discount the importance of deliberation, but rather stress that both components together determine outcomes (Brown, 2014). In Roberts et al.'s, words, “mini-publics have the potential to enable fruitful relationships between experts and lay citizens which would enable public scrutiny of expertise and evidence” (2020, p. 4). We propose that deliberation reinforces the understanding that participants gain through passively receiving information by allowing them to actively reflect, ask questions and apply newly acquired knowledge in the context of a discussion.

Interviews conducted with 11 members of the Assembly in the context of a larger research project offer some possible insights on this front. When questioned on the relative importance of the information and deliberation phases for their decision-making, most interviewees credited "a mixture" of both: "When somebody is just giving you information, you can retain it, you are learning it, but it is not in practice, whereas if you are actually discussing it, you are trying to look at pros and cons of different things, and then obviously you would ask questions and you get a response. I think that was the most important part, was, is, the most important part of the process, in my opinion." 
Another key finding of our study, which currently lacks theorisation in the literature, is that there were some differences in the paths to success for experts and non-experts. While the former were successful when they presented a high number of proposals, the latter were successful when they presented few proposals, even without repetition by others. An important implication of this is that organisers of citizens' assemblies should encourage the participation of individuals who can connect with audiences on 'real-life' climate action and focus on a simple, unique message. This idea is illustrated by an example from a reflective exercise by a member: ${ }^{6}$ Lock the scientists away and get the practitioners to the forefront [...] Bin the scientism and promote pragmatism through the plain-speaking, uncontroversial and successful practitioners.' While this may be an extreme opinion, it suggests that non-expert witnesses are well positioned to tap into the everyday concerns and values of citizen deliberators and highlights the need to include a range of expert and non-expert presenters at such fora. We call for future research to further explore this puzzling finding, test our speculative hypotheses and develop appropriate theory.

Third, this study is, to the best of our knowledge, the first to operationalise and employ the six principles contained in the handbook for IPCC authors. Our experience shows that the handbook guidelines are a useful resource for measuring effective climate change communication (at least) in deliberative settings. Although the systematic validation of the instruments built upon the principles is beyond the scope of this paper (a method paper would be the most appropriate for this purpose), our coding results have produced a broad range of speaker scores, thereby implying that the guidelines

\footnotetext{
${ }^{6}$ The objective of this reflective exercises conducted at the end of the deliberation weekends was "to allow the Members to make comments and suggestions" about the discussed topics and the assembly (see Citizens’ Assembly, 2018, p.7).
} 
capture something meaningful. The ICA case provides a conservative test for this purpose, as the speakers were carefully chosen (see p15), which makes the variance obtained from our results even more interesting.

These contributions notwithstanding, this research has several limitations. First, our design does not allow us to disentangle the effects of information and deliberation or examine the relative importance of each. Information provided by the speakers during the first stage was subject to discussion during small group deliberations, which may have made the effect of information on citizens' judgements more or less strong. Second, we cannot discount the alternative explanation to our findings that effective communicators may have put forward 'convincing arguments' which eventually led citizens' uptake of their policy proposals, as deliberative democrats would have expected. In other words, it could have been the arguments themselves, rather than the effective communication style, that had an effect. While we do not argue that it is impossible, our design does not allow us to objectively evaluate the quality of the arguments advanced by experts. Future research could shed more light on this question.

A further limitation of the single-case approach is that it is situated within a specific political-cultural context. We therefore call for additional studies that may allow for greater generalisation than is possible from a single case study. Fourth, this research design does not say anything about final policy success: the recommendations do not automatically translate to policy change, although some of the Irish recommendations have already been enacted into law. Future research could shed more light on these questions, with alternative research designs, also disaggregated to (for example) the level of individual proposals. Finally, we use an indirect measure of effective communication. Future research 
could combine these guidelines with more direct measures, for example self-reported measures of participants' assessments of different speakers' effectiveness.

\section{References}

Baekkeskov, Erik and PerOla Öberg. 2017. "Freezing deliberation through public expert advice". Journal of European Public Policy, 24: 7, 1006-1026.

Bächtiger, André, John S. Dryzek, Jane Mansbridge, and Mark Warren. 2018. The Oxford Handbook of Deliberative Democracy. Oxford: Oxford University Press.

Beauvais, Edana. 2019. "Discursive Inequity and the Internal Exclusion of Women Speakers.” Political Research Quarterly, 1-14.

Cacioppo, and Richard E. Petty. 1989. Effects of message repetition on argument processing, recall and persuasion. Basic and Applied Social Psychology 10 (1): 3-12.

Carroll, Rory. 2019. "Ireland to Unveil Bold Plan to Tackle Climate Emergency.” The Guardian, 2019. https://www.theguardian.com/world/2019/jun/17/ireland-to-unveil-bold-plan-to-tackle-climateemergency.

Citizens' Assembly. 2018. “Third Report and Recommendations of the Citizens' Assembly: How the State can make Ireland a leader in tackling climate change." Available at: https://www.citizensassembly.ie/en/how-the-state-can-make-ireland-a-leader-in-tackling-climatechange/final-report-on-how-the-state-can-make-ireland-a-leader-in-tackling-climate-change/climatechange-report-final.pdf

Coleman, Martha, Laura Devaney, Diarmuid Torney, and Pat Brereton. 2019, June 27. "Ireland's world-leading citizens' climate assembly. What worked? What didn't?” Climate Change News. 
https://www.climatechangenews.com/2019/06/27/irelands-world-leading-citizens-climateassembly-worked-didnt/

Corner, A., C. Shaw, and J Clarke. 2018. Principles for Effective Communication and Public Engagement on Climate Change: A Handbook for IPCC Authors. Oxford: Climate Outreach.

Dabry, Megan. 2019, June 18. “Ireland to 'nudge' its way to net zero emissions by 2050”. Climate Home News. https://www.climatechangenews.com/2019/06/18/ireland-nudge-way-net-zeroemissions-2050/

Devaney, Laura, Brereton, Pat, Torney, Diarmuid, Coleman, Martha, Boussalis, Constantine, and Travis Coan. 2020. Environmental Literacy and Deliberative Democracy: 2 A content analysis of written submissions to the Irish Citizens' Assembly on climate change. Unpublished manuscript.

Drews, Stefan, and Jeroen C.J.M. van den Bergh. 2016. "What Explains Public Support for Climate Policies? A Review of Empirical and Experimental Studies." Climate Policy 16 (7): 855-76.

Dryzek, John S. 2010. Foundations and Frontiers of Deliberative Governance. Oxford: Oxford University Press.

Ernst, Nicole, Rinaldo Kühne, and Werner Wirth. 2017. "Effects of Message Repetition and Negativity on Credibility Judgments and Political Attitudes." International Journal of Communication 11: 3265-85.

Farrell, David M., Jane Suiter, and Clodagh Harris. 2019. "Systematizing' Constitutional Deliberation: The 2016-18 Citizens’ Assembly in Ireland.” Irish Political Studies 34 (1): 113-23.

Fournier, Patrick, Henk van der Kolk, R. Kenneth Carty, André Blais, and Jonathan Rose. 2011. When Citizens Decide: Lessons From Citizen Assemblies on Electoral Reform. Oxford: Oxford University Press. 
Goertz, Gary. 2006. “Social Science Concepts: A User’s Guide.” Princeton: Princeton University Press. Goodin, Robert E., and Simon J. Niemeyer. 2003. "When Does Deliberation Begin? Internal Reflection versus Public Discussion in Deliberative Democracy.” Political Studies 51 (4): 627-49.

Harring, Niklas, Sverker C. Jagers, and Simon Matti. 2019. "Higher Education, Norm Development, and Environmental Protection." Higher Education.

Kahan, Dan M. 2015. "Climate-Science Communication and the Measurement Problem." Advances in Political Psychology 36(1): 1-42.

Kahan, Dan M., Ellen Peters, Maggie Wittlin, Paul Slovic, Lisa Larrimore Ouellette, Donald Braman, and Gregory Mandel. 2012. “The Polarizing Impact of Science Literacy and Numeracy on Perceived Climate Change Risks." Nature Climate Change 2 (10): 732-35.

Kearney, Anne R. 1994. "Understanding Global Change: A Cognitive Perspective on Communicating through Stories." Climatic Change 27: 419-41.

Lockwood, Matthew. 2011. "Does the Framing of Climate Policies Make a Difference to Public Support? Evidence from UK Marginal Constituencies.” Climate Policy 11 (4): 1097-1112.

McHugh, Mary L., 2012. "Interrater reliability: the kappa statistic”. Biochemia Medica.22(3): 276-82

Moezzi, Mithra, Kathryn B. Janda, and Sea Rotmann. 2017. “Using Stories, Narratives, and Storytelling in Energy and Climate Change Research.” Energy Research and Social Science 31 (May): 1-10.

Moser, Susanne C., and Lisa Dilling. 2011. "Communicating Climate Change: Closing the ScienceAction Gap." In Oxford Handbook of Climate Change and Society, edited by John S. Dryzek, Richard B. Norgaard, and David Schlosberg, 161-74. Oxford: Oxford University Press. 
Niemeyer, S J. 2013. "Democracy and Climate Change: What Can Deliberative Democracy Contribute?, Australian Journal of Politics and History ,." Australian Journal of Politics \& History 59 (3)

O’Neill, Saffron, and Sophie Nicholson-Cole. 2009. “'Fear Won’t Do It' Visual and Iconic Representations." Science Communication 30 (3): 355-79.

O’Malley, Eoin, David M. Farrell, Jane Suiter. 2019. “Does talking matter? A quasi-experiment assessing the impact of deliberation and information on opinion change". International Political Science Review. 1-14

Ragin, Charles C. 1989. The Comparative Method: Moving Beyond Qualitative and Quantitative Strategies. Oakland: University of California Press. . 2008. Redesigning Social Inquiry: Fuzzy Sets and Beyond. Chicago: University of Chicago Press.

Roberts, Jennifer J., Ruth Lightbody, Ragne Low and Stephen Elstub. 2020. "Experts and evidence in deliberation: scrutinising the role of witnesses and evidence in mini-publics, a case study." Policy Sciences: Schneider, Carsten Q., and Claudius Wagemann. 2012. Set-Theoretic Methods for the Social Sciences: A Guide to Qualitative Comparative Analysis. Cambridge: Cambridge University Press.

Shaw, Christopher, and Adam Corner. 2017. "Using Narrative Workshops to Socialise the Climate Debate: Lessons from Two Case Studies - Centre-Right Audiences and the Scottish Public.” Energy Research and Social Science 31 (August): 273-83.

Smith, Graham, and Maija Setälä. 2018. "Mini-Publics and Deliberative Democracy." In The Oxford Handbook of Deliberative Democracy, edited by André Bächtiger, John S. Dryzek, Jane Mansbridge, and Mark E. Warren. 
Stevenson, Hayley, and John Dryzek. 2014. Democratizing Global Climate Governance. Cambridge: Cambridge University Press.

Suiter, Jane, David M Farrell, and Eoin O’Malley. 2016. 'When Do Deliberative Citizens Change Their Opinions? Evidence from the Irish Citizens’ Assembly.” International Political Science Review 37 (2): 198212.

Suldovsky, Brianne. 2017, September 26. "The Information Deficit Model and Climate Change Communication". Oxford Research Encyclopedia of Climate Science. Retrieved 14 Mar. 2020, from https://oxfordre.com/climatescience/view/10.1093/acrefore/9780190228620.001.0001/acrefore$\underline{9780190228620-\mathrm{e}-301}$

Torney, Diarmuid, and Roderic O’Gorman. 2019. “A Laggard in Good Times and Bad? The Limited Impact of EU Membership on Ireland's Climate Change and Environmental Policy." Irish Political Studies 34 (4): 575-94. 